\title{
Remediation of Contaminated Sites
}

\author{
I. Panagiotakis $\cdot$ D. Dermatas
}

Published online: 12 February 2015

(c) Springer Science+Business Media New York 2015

Remediation of contaminated sites is one of the most rapidly developing environmental restoration subjects. Site contamination results mostly from past and present anthropogenic activities and it presently constitutes one of the largest environmental liabilities for future generations to bear. The most significant categories of contaminants that are encountered in contaminated sites, typically as mixtures, are petroleum hydrocarbons, halogenated organic compounds, metals and metalloids, radionuclides, and explosives. The process of remediation of contaminated sites is a site-specific phased approach comprising site characterization, risk assessment and remediation technology selection and application. The high cost and complexity of the problem renders remediation of contaminated sites a real challenge for environmental professionals and society altogether, with far ranging implications on industrial, agricultural and other anthropogenic activities and practices in terms of pollution prevention, waste management and their overall sustainability. Although, this is not a new environmental issue, only when incidents such as the Love Canal site in New York and the Lekkerkerk site in the Netherlands were widely publicized in the 1970s, researchers around the globe started intensively studying the contaminated site problem. As a result thousands of contaminated sites have already been identified in most parts of the world, requiring hundreds of billions of US dollars to

\footnotetext{
I. Panagiotakis $(\square)$

ENYDRON - Environmental Protection Services, 1 Ipirou str., 10433 Athens, Greece

e-mail: panagiotakis@enydron.com

I. Panagiotakis - D. Dermatas

School of Civil Engineering, National Technical University of Athens, 9 Iroon Polytechniou str., 15780 Athens, Greece
}

be remediated. The actual problem is even worse since very limited data are yet available for Eastern Europe, Africa, South America, and for key countries such as China and India. In the European Union (EU) alone the number of contaminated sites requiring remediation has been estimated as approximately 250,000 and the potential polluting activities have been expected to have occurred at nearly three million sites. Besides helping us comprehend the magnitude of the contaminated site problem, these numbers underline the significant lack of data for the EU and underscore the apparent differences in reporting among different geographical and other entities, both issues been applicable for the rest of the globe as well. Furthermore, taking into account the large numbers of known or estimated contaminated sites across the world and the huge budgets required for site remediation, the focus should be shifted on those contaminated sites that potentially pose the highest risks to humans and the environment. Thus, there still is a great need in applied research to fill in the aforementioned data gaps, in terms of both the magnitude and potential risk of site contamination and, more importantly, help develop the most cost-effective, yet scientifically sound and innovative, sustainable remediation approaches.

This special issue of the Bulletin of Environmental Contamination and Toxicology hosts both selected papers from the conference session of the 13th International Conference on Environmental Science and Technology (http://cest2013.gnest.org/) that took place in Athens, Greece in September, 2013, and invited contributions from international researchers. This special issue aims not to cover the entire spectrum of this incredibly wide scientific area but present some interesting examples of research that is currently been carried out in several countries around the world on this subject. 
In particular, this special issue is divided into six (6) parts. The first part accommodates two (2) research papers on site characterization case studies, one (1) for Cyprus and one (1) for Singapore. The second part of this special issue comprises three (3) studies on bioremediation; one (1) of them on arsenate-contaminated soil and two (2) of them on trichloroethylene-contaminated groundwater. The following part of this special issue comprises a study on nanoremediation of groundwater contaminated with hexavalent chromium. The next part, which is the largest one, includes a series of studies on phytoremedation for contaminated soil. Finally, this special issue concludes with two (2) studies investigating waste reuse to prevent soil and groundwater contamination.

The Editors of the special issue would like to specially thank the Editor-in-chief of the Bulletin of Environmental Contamination and Toxicology Dr Erin Bennett for his valuable help and co-operation and of course the contributing authors and the reviewers who enabled this publication in the first place. 